\title{
Satellite Communication Applications - An Essential Component to Aeronautical Safety in the Upper Airspace Communication
}

\author{
Abdulaziz Maiwada ${ }^{1,2}$, A. S. Hussaini ${ }^{2,3,4}$, B. A. Mohammed ${ }^{2}$, I.T.E. Elfergani ${ }^{4}$, \\ R.A. Abd-Alhameed ${ }^{2}$, J. Rodriguez ${ }^{4,5}$ \\ ${ }^{1}$ Nigerian Airspace Management Agency, Murtala Muhammed International Airport, Lagos Nigeria. \\ mabdulaziz@nama.gov.ng \\ ${ }^{2}$ University of Bradford, Bradford, BD7 1DP, UK, \\ \{r.a.a.abd, a.s.hussaini7\}@bradford.ac.uk \\ m.b.abubakar1@student.bradford.ac.uk \\ ${ }^{3}$ School of Engineering, American University of Nigeria, Yola \\ ash.hussaini@aun.edu.ng \\ ${ }^{4}$ Instituto de Telecomunicações - Aveiro, Portugal \\ \{i.t.e.elfergani, ash, jonathan\}@av.it.pt \\ ${ }^{5}$ University of South Wales, Pontypridd CF37 1DL, UK \\ jonathan.rodriguez@southwales.ac.uk
}

\begin{abstract}
In Aviation, the field of communication encompasses a broad range of activities which includes the operation of navigational aids on the ground, in the air and in space and the development of associated technical requirements, specification and procedures. Communication equipment consists of radars and landing aids as well as air-ground and ground to ground telecommunication equipment. Radio communications on very high frequency (VHF) and high frequency (HF) plays complementary role and are the backbones of air traffic control operations.

Telecommunication in aviation can be broadly categorized into either aeronautical fixed services (AFS) or aeronautical mobile service (AMS). The paper illustrates AMS and how bulk voice communication between ground and air was achieved using Radio ( $\mathrm{T} x / \mathrm{Rx})$ over Satellite links for aeronautical safety communication in the upper airspace.
\end{abstract}

Keywords: AFS, AMS, VHF Radio, Satellite and Upper airspace

\section{Introduction}

On September $5^{\text {th }} 1991,450$ representatives from 85 nations and 13 international organizations gathered at the headquarters of the International Civil Aviation Organization (ICAO) in Montreal, Canada to consider and endorse a concept for a Future Air Navigation System (FANS) that would meet the needs of the civil aviation community over the next century. The concept, known as Communications, Navigation, Surveillance/Air Traffic Management (CNS/ATM) systems which involves a complex and interrelated set of technologies, dependent mainly on satellite. From the ground, through the airwaves and across the skies, good communication is the key to safety. 
The aviation industry today looks very different than it did few years ago. One of the most innovative areas deals with the so called "upper airspace" above Flight Level 245 (24,500 feet). In African Indian Ocean (AFI) region, satellite technology is used in the upper airspace communication as a result of propagation limitation of the current line of sight radio communication system. This is more at a global level where the whole world is divided into various flight information regions (FIRs) and aircraft when they travel from Africa to Europe pass through multiple FIR`s area control centres (ACC).

The Area Controller managing the FIR requires an efficient and effective communication systems to provide airtraffic services and this brings about the deployment of remote control air-ground (RCAG) radiocommunication techniques which is currently operating in the Western and Central African (WACAF) Region.

\section{Use Cases of Satellite Communication in Aeronautical Environment}

Aeronautical communications supported by satellite includes the following:

- Aitraffic Service and Direct Speech (ATS/DS) between adjacent Flight Information Region (FIRs) for centre to centre coodination.

- Aeronautical Fixed Telecommunication Network (AFTN) for transmission of flight plans, notice to airmen and aeronautical messages among the centres.

- Support for remote air-ground VHF voice communication for the upper airspace.

- GNSS augmentation data transmission.

- Aeronautical Administration support.

- Operational Aeronautical meteorological data exchanges.

- Operational Aeronautical Information Services exchanges.

- Computer to computer data exchanges between ATS Flight Data Processing Systems (FDPS)

- $\quad$ Air/ground data link (VHF or SSR Extended Squitter - ES 1090)

- Non Aeronautical Service (Search and Rescue).

- Airtraffic Service Interfacility Data Communication (AIDC) for notification, coordination and transfer of control between airtraffic service units.

- Airtraffic Services Message Handling Systems (AMHS) for data communication.

Aeronautical Fixed Services (AFS): refers to the telecommunication between fixed points or ground stations, primarily for Aviation, such as between two airtraffic control units commonly referred to as ground to ground communication. Satellite links is used to ensure centre to centre data exchange. AFS is used in the implementation of aeronautical fixed telecommunication network (AFTN), airtraffic service message handling service (AMHS) and airtraffic Interfacility data communication (AIDC) systems.

Aeronautical Mobile Services (AMS): refers to telecommunication between aeronautical stations on the ground and aircraft stations commonly referred to as air-ground communications Satellite is used to augment the terrestrial radio network for enhancement of communication between area control centre and airplanes flying at higher altitude. This service is usually provided by the air navigation service providers (ANSPs) to implement RCAG systems which is our focus on this paper. 


\section{Remote Control Air-Ground (RCAG) Communication Systems:}

The RCAG is a facility used for air-ground communications of radios systems controlled remotely at the ACC. This allows direct communication from the control centre to network of terrestrial radios located at remote ends. This technology has been in existence for some time to provide communication between Pilots and Airtraffic Controller over a specific designated operation coverage (DOC) of the upper airspace. We are going to look into how to improve the performance of the network for better service.

The aeronautical terrestrial VHF air band in frequency range of 118-137 MHz and Geostationary satellite in orbit constitutes RCAG system shown in Figure 1.

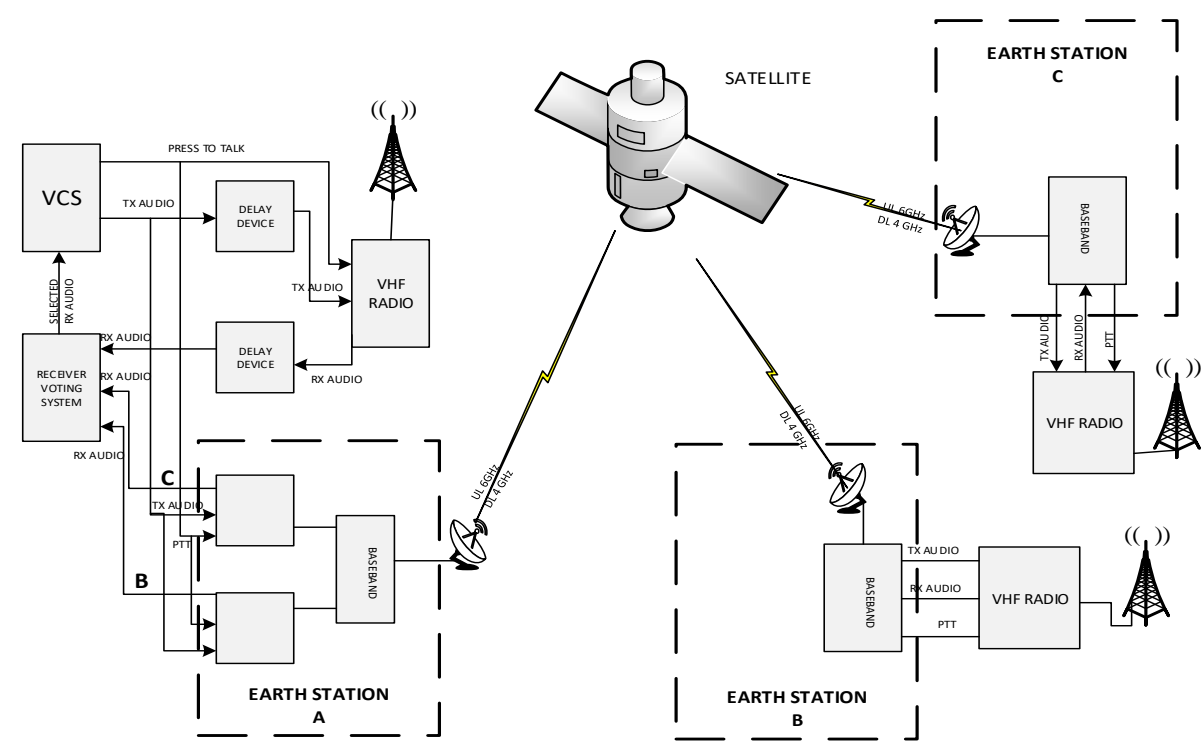

Figure 1: Remote Control Air to Ground Systems

During transmission, the Controller keys the press to talk (PTT) button from voice communication system (VCS). The signals are delayed for transmission over the satellite to Earth stations A and B by the Delay Device. The time of travels in millisecond by which the signals travel through the satellite is preset in Delay Device so that the PTT signal activates the 3 radios attached to Earth Station A,B and C at the same time.

On reception, the receiver voting systems compare and select the best from 3 received signals and the strongest is voted and received at VCS console by the Area Controller.

When two or more radios are connected over the satellite for the purpose of communication, the region where the radiation pattern overlaps is of main concern. There is bound to be interference in the form of echo if mitigation is not applied to correct it. The offset frequency technique is introduced to remove repetitive conversation of transmission/reception of Controller and Pilot. Offset is the difference between receive and transmit frequencies of a radio channel. Most commonly it refers to the separation between the input frequency and output frequency of a repeater or other type of full duplex system. Zero, positive and negative offsets are selected on the radios depending on the numbers of sites in the network which is going to be explained further later in this paper. 
One of the important factors is latency which results to propagation delay through the satellite and the processing delay in the equipment. RCAG time of propagation delay measurement and settings are normally carried out during station commissioning and recorded. For the measurement, a time counter and a device with PTT, Tx \& Rx wires are required by connecting the device to terminals on the satellite main distribution frame (MDF). In the modems of the corresponding stations make an IF loop and press PTT. The counter takes in account the go and return signals and measure time which will be used to preset the delay time for the remote sites. The value is normally between 400 to 500 milliseconds depending on the distance of the satellite from the earth.

A radio high gain antenna installed on mast of 30 metres (100ft) can provide an omnidirectional coverage of more then 200 Nautical mile at 50Watt power output. Care should be taken to adjust the power, in order to minimize the area of overlap also avoid blind spots which means that geographical site of radio installation should be carefully selected.

Despite the enormous advantages offered by satellites, it also has a number of limitation against its proper use. The limitations include signal latency, rain fade, line of sight and fresnel zone. Latency is one of the main factors affecting the performance of this remote control air-ground technology and this paper works on structural approach on how to improve on the integrity and performance of this system.

\section{Satellite Performance Monitoring Technique}

In order to monitor the performance of the entire satellite network, ICAO-APIRG/18 meeting held in 2012 endorsed a performance monitoring strategy based on a four levels reporting index. The diagram in Figure 2, a detailed network architecture which evaluate performance of various device in the satellite link.

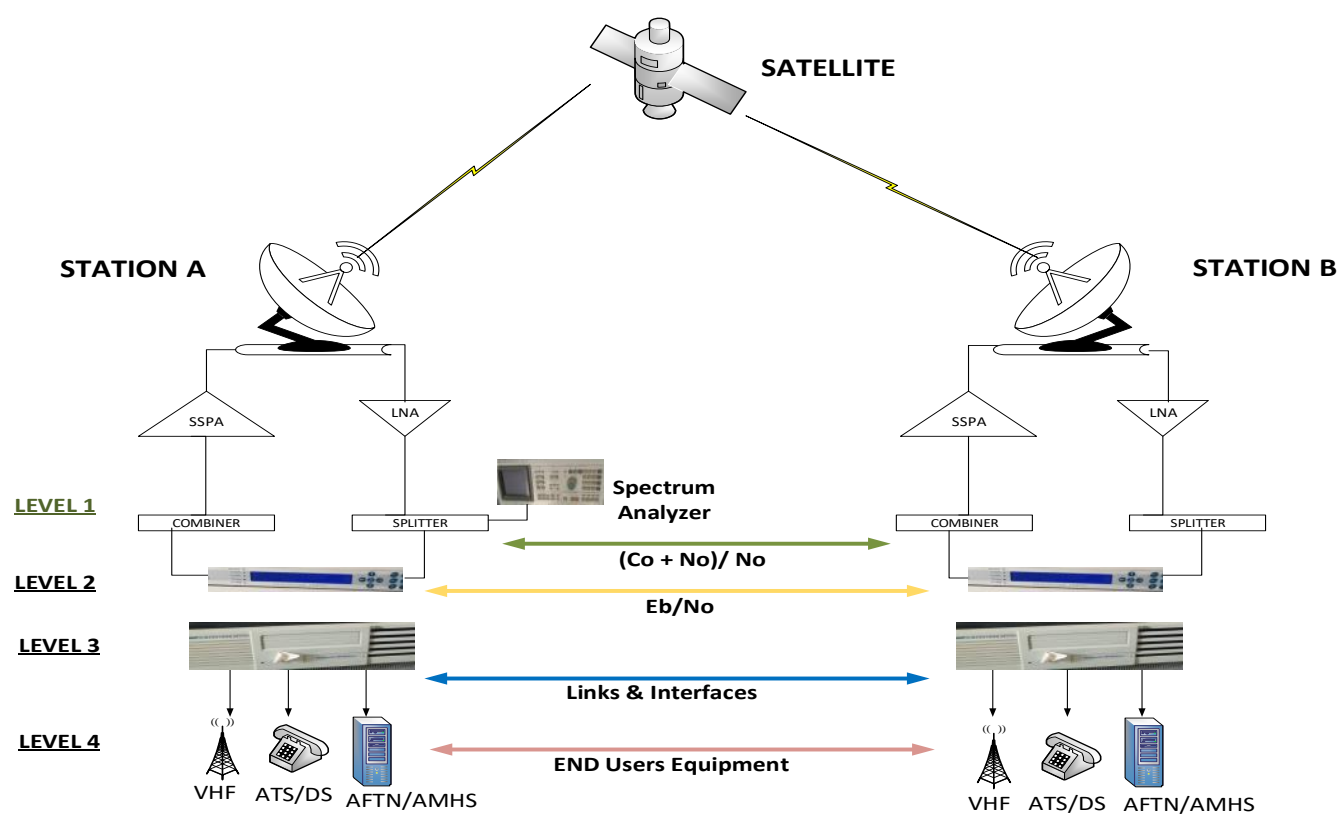

Figure 2: Satellite Communication Network for Evaluation of the System Performance 
- Level 1: Space segment $(\mathrm{Co}+\mathrm{No}) / \mathrm{No}$

- Level 2: Radio frequency and related equipment Eb/No

- Level 3: Multiplexers or interfaces base band equipment

- Level 4: User Terminal Equipment (Radio, telephone, radar data etc.)

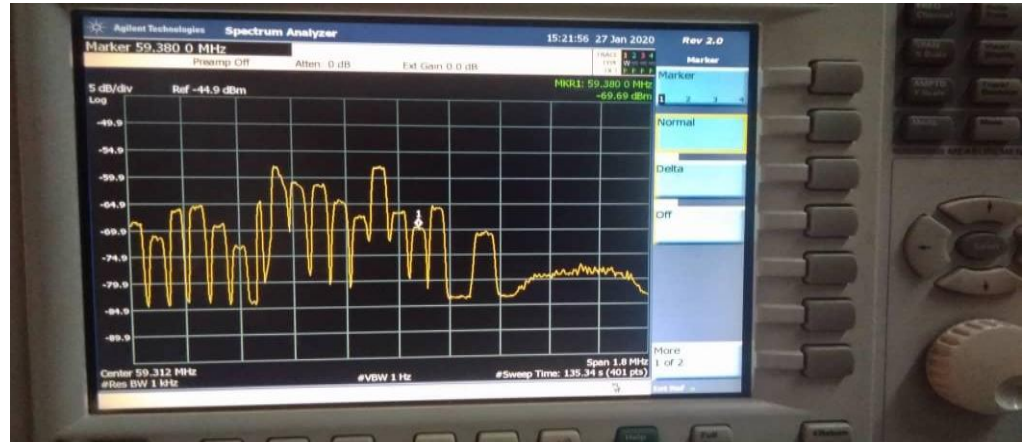

Figure 3: Measurement of $(\mathrm{Co}+\mathrm{No} / \mathrm{No})$ with Spectrim Analyzer

\section{Structured Approach to the Work on Improving the Performance of the RCAG Systems}

We propose a system that will provide an ultra-low latency with high efficiency and good Quality of Service (QoS) for the upper airspace communication. Each device in a network is guilty of slowing the overall end-to-end flow of information, contributing some tangible amount to the total processing delay. Since the speed of light is fixed and the choice of satellites often is limited, our attention was focused to network design and individual components and their associated configuration to minimize network latency. As noted earlier, every device interconnected in a network has some adverse effect on end-to-end latency. Many devices are highly configurable and designed to serve a wide range of applications. Keep in mind that a different configuration may result in lower latency, and there are multiple areas to consider. Owing to the technology advancement, the on-going evolution of $5 \mathrm{G}$ standards, this provides a unique opportunity to improve latency over on the satellite. Figure 4, shows a network diagram and evaluate the processing delay associated with every device and options which may save significant time of the latency being experienced, thereby improving network performance. The use of internet protocol (IP) based radios and VCS with the high speed satellite modems are integrated to achieve this. 


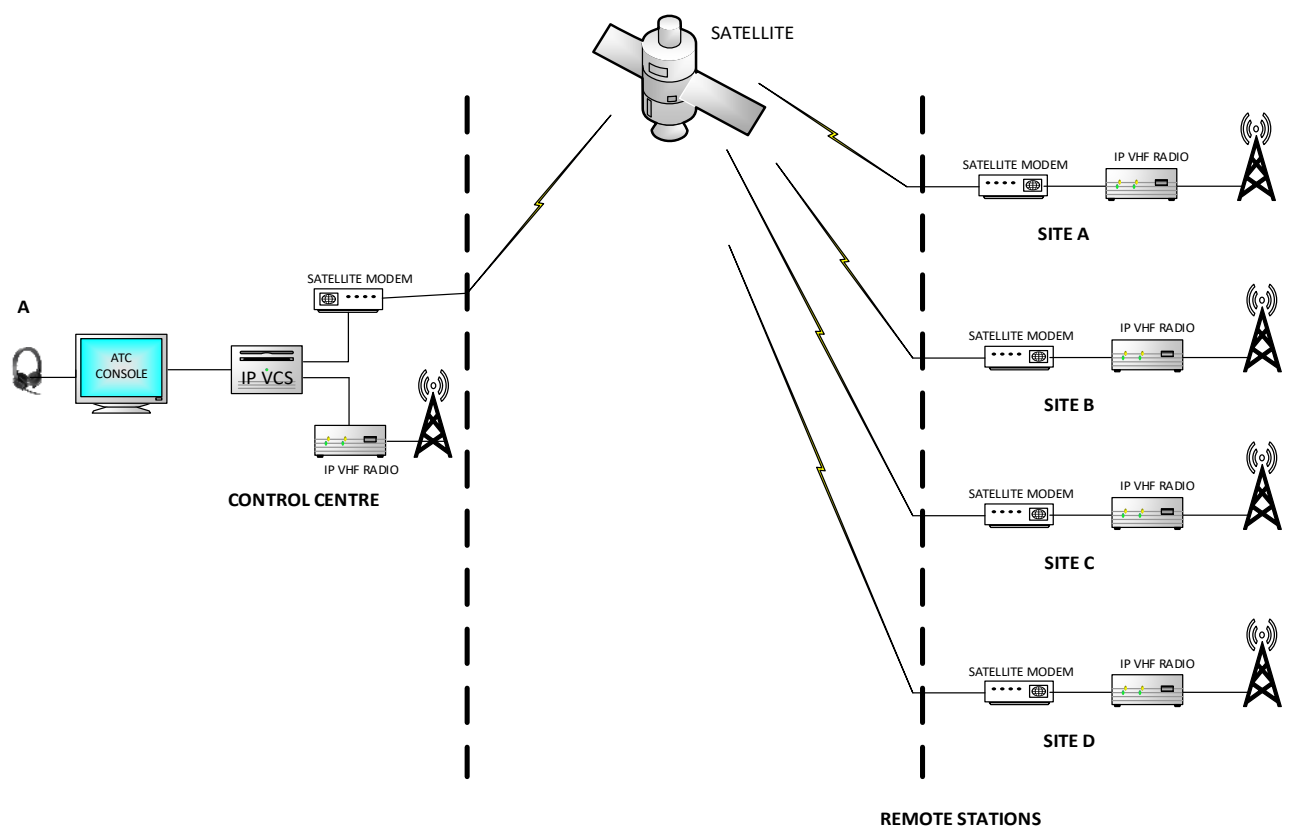

Figure 4: Overview of IP Based Remote Control Air-Ground Radio Communication Systems

The IP technology improvement is capable of supporting a broad variety of air traffic management applications including radar data information, voice communication for radio/telephone and satellite communication.

In Figure 5, the VCS combines feature of the shortest audio and signalling delay times with advanced routing principles, without compromising established quality and safety levels. It also has an integral best signal selection (BSS) for voting the best audio quality and provision for offset carrier frequency adjustment with two-way dynamic delay compensation.

Ground Radio Station (Tx/Rx) supports ED-137 VoIP standards wth telephone and radio interfaces, enabling deployment exactly as required for operational needs.

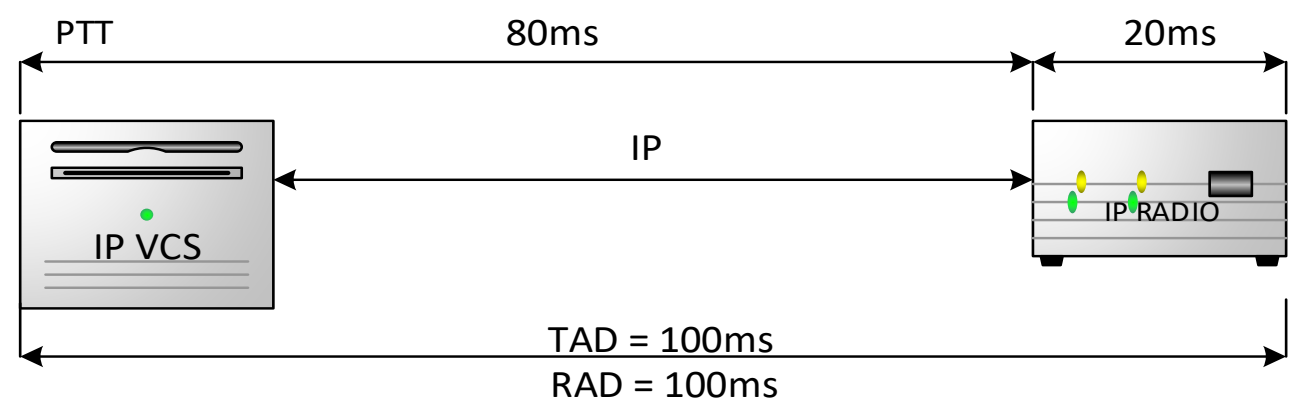

Figure 5: Transmitter and Receiver Delay between VCS and Radio Transceiver

The VCS establish communication with radios in the control centre and other IP networks over the satellite using SIP and RTP as specified in the document ED-137 Volume 1 "Interoperability Standards for VoIP ATM Radio Components". The transmitter activation delay (TAD) and 
receiver activation delay (RAD) equal to $100 \mathrm{~ms}$ and this is the equipment processing delay which should be considered when calculating overall latency.

The MF-TDMA satellite modem incorporates a comprehensive router supporting interior \& exterior routing protocols and MPLS providing a seamless integration into user networks. The fully IP-based system provides seamless integration to terrestrial IP networks on both ends, the central hub, and the remote terminals with high processing speed. A non-compressed codec, less susceptible to packet loss, ITU-G.711 standards should also be considered to maintain better quality with more latent connections.

To check time and get a true reading of the satellite latency, find a suitable device you can perform a trace route to search and this will show the connected equipment in the route. You can pick a device just after the satellite link and ping to check the latency times.

You can also calculate the latency over the link using the basic speed, distance and time equation.

$$
\begin{aligned}
\text { Speed } & =\text { distance } / \text { time }(\mathrm{m} / \mathrm{s}) \\
\text { Time } & =\text { distance } / \text { speed }(\mathrm{t})
\end{aligned}
$$

Radio Frequency (RF) waves travel at the speed of light which is a little less than $300,000 \mathrm{~km}$ per second $(299,792.458 \mathrm{~km} / \mathrm{s})$. Considering geostationary satellite located $36000 \mathrm{~km}$ above the equator, the time can be calculated thus;

$$
\frac{36000}{299792}=0.1200 \mathrm{sec}
$$

Therefore, the time for the RF signal to reach the satellite is 0.120083 seconds and for a signal or information to travel across a satellite link is 0.240166 seconds. This mean that one hop is 240 milliseconds while two way (go and return) is approximately 480 milliseconds. This is the propagation delay which is due to the distance between the ground and the satellite. Please note that the values varies in accordance to the distance of the satellite to the earth.

Latency time of a satellite link is a crucial factor when choosing to use a satellite system, it can affect the performance of your network and some applications like the RCAG experience issues when the latency is too high, and this is not good for the air traffic control operations.

\section{Operation Coverage of Radio in Various Carrier Offset Mode}

Another important factor in the RCAG systems is the frequency offset. Offset frequency is a variation of single channel simplex wherein telecommunication between two stations is effected by using in each direction frequencies that are intentionally slightly different but contained within a portion of the spectrum allotted for the operation. The offset must be set on both VCS and radio equipments to enhance compatibilty and avoid repeatitive speech during communication with aircraft in the overlap region of the designated operation coverage. The overlap can be seen in the diagram as shown in Figure 6. 


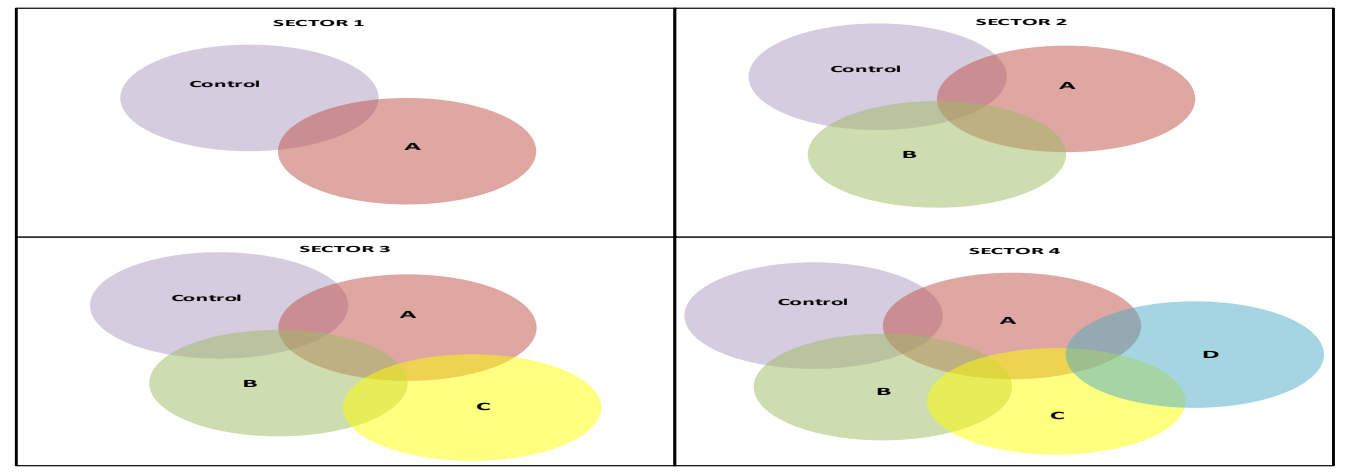

Figure 6: Geographical Distribution of Common Frequency Radios Using Satellite

Offset carrier systems can be used in $25 \mathrm{kHz}, 50 \mathrm{kHz}$ and $100 \mathrm{kHz}$ channel spaced environments. The stability of individual carriers of an offset carrier system shall be such as to prevent firstorder heterodyne frequencies of less than $4 \mathrm{kHz}$ and, additionally, the maximum frequency excursion of the outer carrier frequencies from the assigned carrier frequency shall not exceed $8 \mathrm{kHz}$.

Table 1: Offset Carrier Operation

\begin{tabular}{|l|l|l|}
\hline Geo Coverage & Mode & Frequency $(\mathbf{K H z})$ \\
\hline Sector 1 & Offset -2 & +5 and -5 \\
\hline Sector 2 & Offset -3 & $+7.3,0,-7.3$ \\
\hline Sector 3 & Offset -4 & $+2.5,-2.5$ and $+7.5,-7.5$ \\
\hline Sector 4 & Offset -5 & $+4000,-4000,0+8000,-8000$ \\
\hline
\end{tabular}

Assigment of correct offset frequency is very critical to succesfull operation of the RCAG systems. The polarity of offset assignment on the radio should correspond with the setting in the VCS.

\section{Research on Radio Readability Test in Upper Airspace Communication}

The research design of this work is based on conversations between airtraffic controller (ATC) and airline pilot on aircrafts movemet in the upper airspace for certain duration irrespective of aircraft type and taking into cognizance of the different Flight levels, Range in Nautical Miles and Heading in Degrees. The methodology used was through submission of format specifically designed for readability test during flight and feedback was recorded. Sample of flight data over some interval of time was collected for analysis as shown in Table 2. 
Table 2: Statistics of Airtraffic Movement in The Upper Airspace Control

\begin{tabular}{|c|c|c|c|c|c|c|c|}
\hline Date & $\begin{array}{c}\text { Time } \\
\text { (UTC) }\end{array}$ & $\begin{array}{l}\text { Aircraft } \\
\text { Callsign }\end{array}$ & $\begin{array}{c}\text { Range } \\
\text { (NM) }\end{array}$ & $\begin{array}{c}\text { Altitude } \\
\text { (FEET) }\end{array}$ & $\begin{array}{c}\text { Heading } \\
\text { (DEGREES) }\end{array}$ & $\begin{array}{c}\text { Aircraft } \\
\text { Readability }\end{array}$ & $\begin{array}{r}\text { Controller } \\
\text { Readability }\end{array}$ \\
\hline $11 / 03 / 2020$ & 0740 & DAN0333 & 232 & FL 249 & 101 & 4 & 4 \\
\hline $11 / 03 / 2020$ & 0753 & APK7191 & 191 & FL 216 & 290 & 4 & 4 \\
\hline $11 / 03 / 2020$ & 0814 & APK7573 & 165 & FL 187 & 166 & 4 & 4 \\
\hline \begin{tabular}{|l|}
$11 / 03 / 2020$ \\
\end{tabular} & 0817 & DAN0361 & 247 & FL 259 & 185 & 4 & 4 \\
\hline $11 / 03 / 2020$ & 0841 & ARA761 & 240 & FL 089 & 013 & 4 & 4 \\
\hline $11 / 03 / 2020$ & 0847 & DAN0334 & 302 & FL 121 & 301 & 4 & 3 \\
\hline $11 / 03 / 2020$ & 0906 & UAE0767 & 321 & FL 320 & 283 & 3 & 3 \\
\hline $11 / 03 / 2020$ & 0915 & IAN4101 & 205 & FL 322 & 112 & 4 & 4 \\
\hline $11 / 03 / 2020$ & 0928 & DA463 & 251 & FL 230 & 020 & 4 & 4 \\
\hline $11 / 03 / 2020$ & 0928 & T4NMN & 198 & & & 4 & 4 \\
\hline $11 / 03 / 2020$ & 0936 & NIG382 & 244 & FL 330 & 012 & 4 & 3 \\
\hline $11 / 03 / 2020$ & 0942 & $5 \mathrm{NB} 00$ & 238 & FL 240 & 184 & 4 & 3 \\
\hline $11 / 03 / 2020$ & 0945 & APK7152 & 241 & FL 265 & 185 & 4 & 5 \\
\hline $11 / 03 / 2020$ & 0946 & ETH921 & 348 & FL 400 & 179 & 4 & 4 \\
\hline $11 / 03 / 2020$ & 0947 & ETH546 & 340 & FL 380 & 280 & 4 & 4 \\
\hline $11 / 03 / 2020$ & 0947 & KQA502 & 325 & FL 300 & 303 & 4 & 4 \\
\hline $11 / 03 / 2020$ & 1004 & NIG196 & 202 & FL 160 & 164 & 4 & 4 \\
\hline $11 / 03 / 2020$ & 1018 & ETH917 & 349 & FL 400 & 278 & 4 & 4 \\
\hline $11 / 03 / 2020$ & 1051 & $5 \mathrm{NBOO}$ & 247 & FL 230 & 009 & 5 & 4 \\
\hline $11 / 03 / 2020$ & 1058 & $5 \mathrm{NB} 00$ & 255 & FL 230 & 007 & 3 & 1 \\
\hline $11 / 03 / 2020$ & 1206 & AZM2363 & 233 & FL 260 & 207 & 3 & 3 \\
\hline $11 / 03 / 2020$ & 1209 & NIG314 & 178 & FL 244 & 296 & 3 & 3 \\
\hline $11 / 03 / 2020$ & 1219 & DAN0368 & 250 & FL 111 & 026 & 2 & 3 \\
\hline $11 / 03 / 2020$ & 1221 & DAN0367 & 230 & FL 279 & 183 & 3 & 3 \\
\hline $11 / 03 / 2020$ & 1224 & DAN0368 & 245 & FL 226 & 010 & 2 & 3 \\
\hline $11 / 03 / 2020$ & 1236 & KQA563 & 262 & FL 370 & 115 & 3 & 3 \\
\hline $11 / 03 / 2020$ & 1237 & ETH934 & 252 & FL 390 & 087 & 3 & 3 \\
\hline $11 / 03 / 2020$ & 1240 & APK7171 & 220 & FL 176 & 212 & 1 & 1 \\
\hline $11 / 03 / 2020$ & 1248 & OMBT7401 & 240 & FL 222 & 012 & 4 & 3 \\
\hline $11 / 03 / 2020$ & 1302 & 3NBLA & 227 & FL 122 & 329 & 4 & 4 \\
\hline
\end{tabular}




\begin{tabular}{|l|l|l|l|l|l|l|l|}
\hline $11 / 03 / 2020$ & 1314 & DAN0334 & 207 & FL 185 & 333 & 3 & 3 \\
\hline $11 / 03 / 2020$ & 1316 & APK7144 & 246 & FL 257 & 183 & 3 & 3 \\
\hline $11 / 03 / 2020$ & 1323 & ETH920 & 303 & FL 410 & 098 & 3 & 3 \\
\hline $11 / 03 / 2020$ & 1329 & ETH900 & 248 & FL 350 & 076 & 3 & 3 \\
\hline
\end{tabular}

Source: Lagos Area Radar Control Centre. (www.nama.gov.ng)

\subsection{Data Analysis}

Data was analyzed with Microsoft Excel 2013 application software to produce readability graph and chart as represented in Figure 7 and Figure 8 respectively. Aircraft readability is displayed in blue line while Controller readability in brown colour.

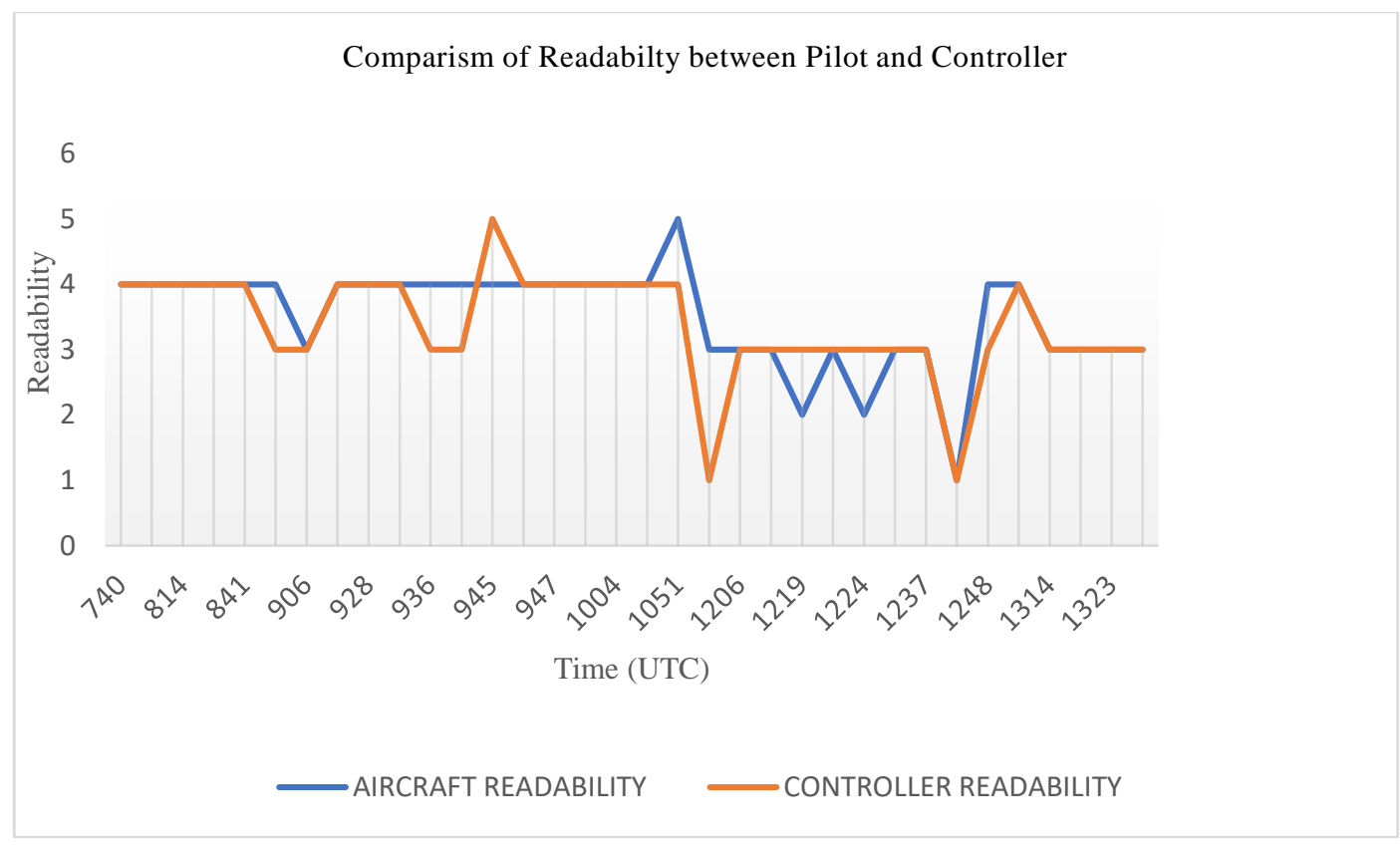

Figure 7: Graph of Readability Test

Further analysis was carried out which resulted in the presention of radio readability Bar chart shown in Figure 8. 


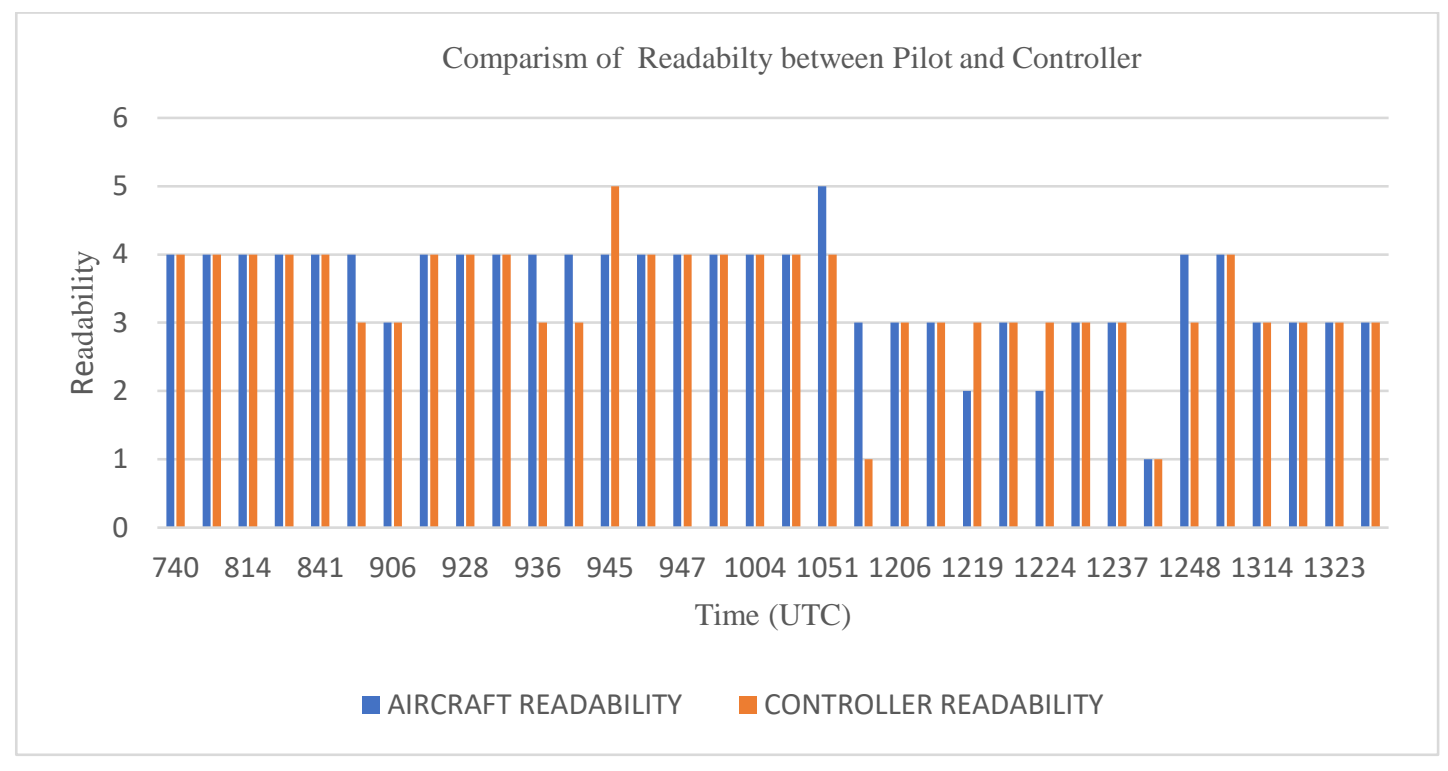

Figure 8: Chart of Readability Test

\subsection{Evaluation of Result}

From the research, it was observed that the communication during the morning period was better than afternoon which could be as a result either hardware defect or environmental/weather factor. The speech quality is evaluated using score indicated in Table 3. The impairement was confirmed by the Pilot and Controller based on their pychological pysche. The airtraffic operations in the morning witnessed 'Good' communication because most of the conversations are 'Readable' while communication in the afternoon was 'fair' because both parties 'Read with difficulty`.

Table 3: Degree of Readability

\begin{tabular}{|l|l|l|}
\hline Readability & Quality & Impairement \\
\hline 5 & Excellent & Very Readable \\
\hline $\mathbf{4}$ & Good & Readable \\
\hline $\mathbf{3}$ & Fair & Reading with Difficulty \\
\hline 2 & Poor & Readable now and then \\
\hline 1 & Bad & Unreadable \\
\hline
\end{tabular}

\subsection{Results and Findings}

From the findings, it was observed that the cooling systems in the shelter where the RCAG equipment is remotely located was ineffective. The ineffectiveness degraded the performance one of the units called modem. Applying performance monitoring strategy based on a four levels reporting index in Figure 2, and after troubleshoot was done at Level-2, we found out that, the 
bit error rate (BER) has gone very high with low Eb/No. The alarms are displayed as recorded in the Systems Log.

From this research, environment is an important factor for the optimal performance. It is therefore, recommended that, when deploying a system, ambient temperature should be put into consideration. Make sure you check datasheet/specifications and select the equipment that is suitable or adaptable to your environment.

\section{Conclusion}

The paper review different works in the area and identified some factors that would improve the performance and enhance safety of aeronautical communication in the upper airspace. The performance of the RCAG radio communication systems can be enhanced by reducing hardware`s point of failure through system integration which would save significant time from latency, thereby providing quality of speech for upper airspace control operations.

\section{References}

[1]. V. Galotti, International Civil Aviation Authority, Future Air Navigation Systems (FANS), Communication, Navigation, Surveillance and Air Traffic Management, Chapter 1, page 3, 1997.

[2]. Ogundele A. Daniel Ayansola, Understanding Satellite Communications, Chapter 5, 1.2.2 page 5, 2010.

[3]. ICAO, Annex 10, Aeronautical Telecommunication. Volume III, Communiacation Systems, Second Edition July 2007.

[4]. ICAO, Annex 10, Aeronautical Telecommunication. Volume II, Communiacation proceedures including those with PANS status, sixth Edition October 2007.

[5]. Greg Berloches, Minimising Latency in Satellite Networking, September 1, 2009.

[6]. ITU-T Rec. G.107, Transmission Systems and Media, Digital Systems and Networks. March 1, 2005.

[7]. ITU-T Rec. G.711, Pulse Code Modulation (PCM) of Voice Frequencies. 1988, 1993.

[8]. ITU-T Rec. G.729, Coding of Speech at 8kbits/sec Using Conjugate-Structure AlgebraicCode-Excited Linear Prediction (CS-ACELP), June, 2016.

[9]. www.satellitetoday.com

[10]. www.nama.gov.ng

[11]. www.voipmechanic.com 